\title{
Correlation between Combined Width of Maxillary Anterior Teeth, Interpupillary Distance and Intercommissural Width in a Group of Indian People
}

\author{
${ }^{1}$ Suryakant Chhagan Deogade, ${ }^{2}$ Sneha S Mantri, ${ }^{3}$ Sudhanshu Saxena, ${ }^{4}$ Hemasha Daryani
}

\section{ABSTRACT}

Purpose: The objective was to evaluate the correlation between the width of distal surface of canine (CWC), interpupillary distance (DMP) and intercommissural width (DCM) in a group of central Indian people.

Materials and methods: A total of 540 central Indian subjects (277 males and 263 females) aged 19 to 30 years were selected. DMP and DCM were measured on subject's face using digital vernier caliper [Mitutoyo (UK) Ltd.] with precision of $0.01 \mathrm{~mm}$. Irreversible hydrocolloid impression of the upper arch was taken, and a cast was poured with dental stone. The CWC measurements were done on these casts with the help of a dental floss fixed between the distoproximal contacts of upper canines using a dental tape. Spearman's correlation test was used to determine the correlation between the three variables studied.

Results: The results revealed that the correlation between CWC-DMP was 0.015 and CWC-DCM was 0.031. The correlation showed negative values when compared between the sexes. Also, the proportions were calculated: DMP/CWC and $\mathrm{DCM} / \mathrm{CWC}$ for the whole sample and for the sexes found no statistical significance $(p>0.05)$.

Conclusion: The results of this study suggest that the examined interpupillary distance and intercommissural width cannot be considered reliable guidelines in the selection of artificial upper frontal teeth. However, they may be used as a useful additional factor combined with other methods for objective teeth selection in complete denture therapy.

Keywords: Complete denture, Intercanine, Intercommissure.

How to cite this article: Deogade SC, Mantri SS, Saxena S, Daryani H. Correlation between Combined Width of Maxillary Anterior Teeth, Interpupillary Distance and Intercommissural Width in a Group of Indian People. Int J Prosthodont Restor Dent 2014;4(4):105-111.

\footnotetext{
${ }^{1,2}$ Professor, ${ }^{3,4}$ Senior Lecturer

1,2Department of Prosthodontics and Crown and Bridge Hitkarini Dental College and Hospital, Jabalpur, Madhya Pradesh, India

${ }^{3,4}$ Department of Public Health Dentistry, Hitkarini Dental College and Hospital, Jabalpur, Madhya Pradesh, India
}

Corresponding Author: Suryakant Chhagan Deogade Professor, Department of Prosthodontics, Hitkarini Dental College and Hospital, Jabalpur, Madhya Pradesh, India, Phone: 9907348038, e-mail: dr_deogade@yahoo.co.in

\section{Source of support: Nil}

Conflict of interest: None

\section{INTRODUCTION}

Esthetics is one of the major concerns for patients seeking complete removable prosthesis for their missing teeth. The basic goal of complete denture therapy is to achieve the maxillary frontal teeth restored to optimal dentolabial relations in harmony with the overall facial appearance. To achieve this goal, the dimension, morphology and arrangement of the frontal teeth must be in proportion to the facial dimension. In completely edentulous patients, it is a real challenge for a prosthodontist to successfully place the denture teeth in the same position as natural teeth and conform to the normal physiological oral activities.

During bite registration, while fabricating complete denture, various indicator lines, such as center line, high lip line, smile line and canine line, are marked on the bite blocks. These guidelines assist the clinician in determining the correct distoproximal size of the frontal teeth. The placement of these lines is based on reference to certain definite facial landmarks, such as intercommissure, interalar, the labial frenum, bizygomatic width and interpupillary distance. ${ }^{1-5}$ In the absence of pre-extraction records, ${ }^{6}$ these facial and oral anatomical landmarks can be of utmost important for the clinician. The relative position of the canine while arranging the artificial denture teeth is critically important as it supports the corner of the mouth. Furthermore, it is the turning point of the dental arch which makes its position as the principal factor in considering complete denture esthetics. This also can provide valuable information for selecting the distoproximal size of maxillary frontal teeth.

Several guidelines are suggested for marking the canine line on the maxillary bite block. Some authors ${ }^{7-9}$ have suggested that the approximate location of the distal surface of the upper canines can be indicated by marks made on the upper bite block at the corner of the mouth. The canine line can also be marked by extending the vertical parallel lines from the lateral surface of the alae of the nose on to the labial surface of the upper bite 
block which indicates the estimation of the position of the tip of the upper canine. ${ }^{8,9}$ Also, the projection of a line drawn from the inner canthus of the eye to the alae of the nose passes through the upper canine. ${ }^{10}$ Several authors have conducted the studies in the past 4 to 5 decades for marking the canine line.

Several authors ${ }^{2,11,12}$ have studied the relationship between the anthropometric measurements of the face and the combined width of maxillary anterior teeth. They have recommended a ratio between the facial size and the tooth size that could be used as a guide in selecting artificial denture teeth. But, the main drawback of these measurements is that the soft-tissue measurements are subjective to change. The solution to this problem is the use of stable facial references and that are not subjective to change. One of such stable facial landmark is the interpupillary distance, ${ }^{13,14}$ which does not modify after the age of fourteen.

Gomes et $\mathrm{al}^{15}$ investigated the relationship of interpupillary distance and distoproximal width of upper anterior teeth and suggested that it could help in the selection of the artificial teeth. They found that the interpupillary distance could help reliably for the selection of maxillary anterior teeth. Latta et $\mathrm{al}^{4}$ while studying the North American population found no correlation between intercommissural width, interalar width and interpupillary width. Varjão and Nogueira ${ }^{16}$ studied four different racial groups and found a weak correlation between intercommissural width and disto-proximal surfaces of canines. However, some authors ${ }^{17,18}$ found positive correlation between intercanine tip width and interalar width in their studies. Previous studies have shown that the canine position is based on facial anatomical structures, hence may relate to an individual race. Very few studies regarding the intercanine width to the facial landmarks have been conducted in Asian people especially Indians. The objective of this study was to determine the correlation between maxillary intercanine width and the facial landmarks including interpupillary distance and intercommissural width in a group of central Indian people. The aim was also to calculate the ratio between the measured variables, which could be helpful in clinical practice.

\section{MATERIALS AND METHODS}

Five hundred and forty individuals participated in this study aged from 19 to 30 years. The growth of the craniofacial system and the teeth had to be completed for each individual. The sample consisted of 277 males and 263 females. Individuals with occlusal and orthodontic anomalies, any asymmetry of the face, extractions and fillings on the frontal teeth were excluded from the study. None of the participants had crowding or spacing and fixed crowns on any of the frontal teeth in the upper or the lower jaw.

The measurements were made by using a precise digital vernier caliper [Mitutoyo (UK) Ltd.] with precision of $0.01 \mathrm{~mm}$ and the possibility of measuring distances from 0 to $150 \mathrm{~mm}$. The DMP and DCM measurements were made by one observer, directly on the participants. During the measurement, they sat comfortably in a dental chair in an upright position and, before the beginning of the measurement, they were required to widely open and close their mouth several times and to move their lips to allow fatigue of the surrounding muscles to relax, during the measurement.

During the DMP measurements, the distance between the mid-pupils of the eyes was recorded. During the DCM measurement, the participant had to be relaxed, to look into the distance, the mandible was in the rest position and the lips had to be unstretched. The CWC measurements were completed on the artificial stone casts with the help of a dental floss. The dental floss was fixed between the distoproximal contacts of upper canines with the help of a dental tape and the markings were done with a marker pen. The distance between these markings were measured and recorded as CWC. The same measurement was completed three times over a period of 10 days in 10 participants to test the reproducibility of the measurements. The Kendall W-test (a nonparametric test) was used to test the significance between the three measurements. The Kendall coefficient of concordance was calculated and, for all the measured variables, there was no significant difference between the three measurements ( $p>0.05)$. As there were no significant differences between the measured variables, it was decided that all the other participants should be measured in the same way. Based on the result of pilot study, 5\% level of significance and $80 \%$ power of study, sample size of 540 participants was calculated for present study.

The following variables were measured for each participant: DMP_distance between mid-pupils of eyes, DCM-distance between corners of the mouth, CWC combined width of upper frontal teeth. All the collected data were statistically analyzed by using the statistical package SPSS version 16 for Windows (SPSS Inc, Chicago, Illinois, USA). Standard univariate and bivariate analysis were performed. The mean values $(\mathrm{x})$ and standard deviation (SD) were calculated and the normality of the distribution was tested by one sample Shapiro-Wilk test.

Descriptive statistics were carried out for all 540 participants and then separately for the male and female 
subjects. The proportions between the variables were calculated for each individual (DMP/CWC, and DCM/CWC) as well as the mean values and SDs of the proportions. To test the difference between sexes, bivariate analysis was used for all the measured variables, and then also between the proportions (Mann-Whitney two-sample test).

\section{OBSERVATIONS AND RESULTS}

Mean values and standard deviations of the measured variables (DMP, DCM and CWC) are presented in Table 1 for all participants and also separately for males and females in Table 2. Gender-wise distribution of study subjects is shown in Graph 1. Statistical analysis using the two-sample Mann-Whitney test showed significant difference for all the variables between males and females $(p<0.01)$, i.e. males, had significantly higher values than females. The average age was 22.57 with a range from 19 to 30 years. The mean values of DMP, DCM and

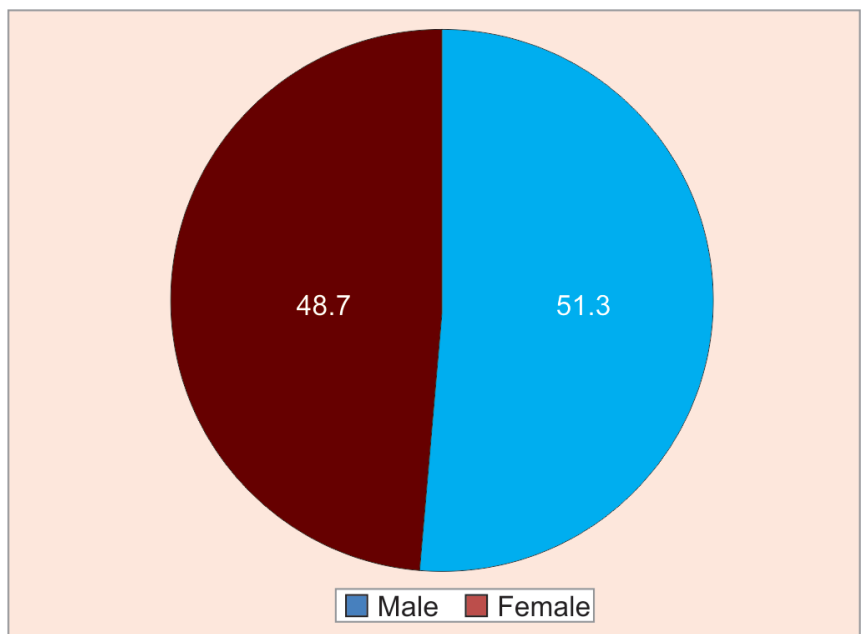

Graph 1: Gender-wise distribution of study subjects (in percentage)

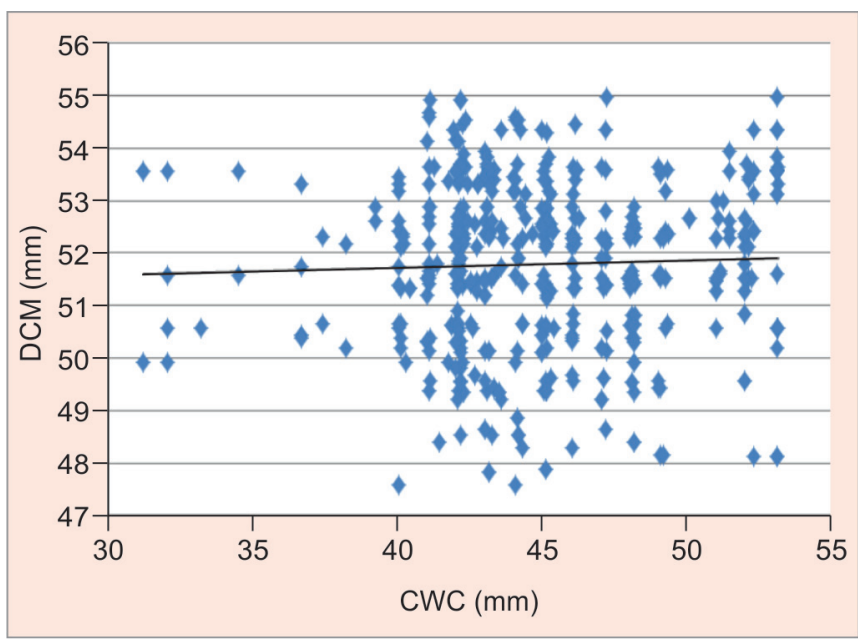

Graph 3: Correlation between CWC and DCM in all subjects
CWC for the whole sample were $62.26 \pm 1.97 \mathrm{~mm}, 51.79 \pm$ $1.56 \mathrm{~mm}$, and $45.04 \pm 4.21 \mathrm{~mm}$ respectively. For males, the mean values of DMP, DCM and CWC were $62.69 \pm$ $2.11 \mathrm{~mm}, 52.25 \pm 1.63 \mathrm{~mm}$ and $45.59 \pm 3.83$ respectively; whereas for females, the mean values were $61.82 \pm 1.70 \mathrm{~mm}$, $51.30 \pm 1.33 \mathrm{~mm}$ and $44.46 \pm 4.52 \mathrm{~mm}$ respectively.

The correlations between the measured variables (DMP, DCM and CWC) were tested with Spearman's correlation test (Table 3, Graphs 2 and 3). For DMP and CWC, the correlation coefficient $(\mathrm{R})$ between sexes was 0.084 (males) and -0.082 (females) (Graphs 4 and 6). For DCM and CWC, it was -0.005 (males) and -0.032 (females) (Graphs 5 and 7). The correlation showed negative values and was found to be weak and statistically not significant. The proportions were calculated: DMP/CWC and DCM/ CWC (Table 2), for the whole sample and then separately for the males and females. There was no significant difference for the proportion $(p>0.05)$ between the males and the females.

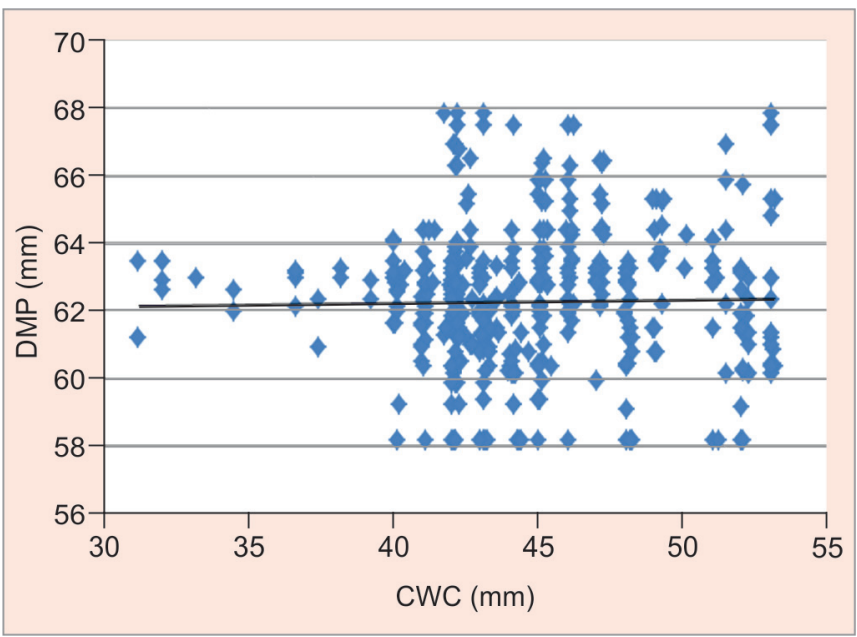

Graph 2: Correlation between CWC and DMP in all subjects

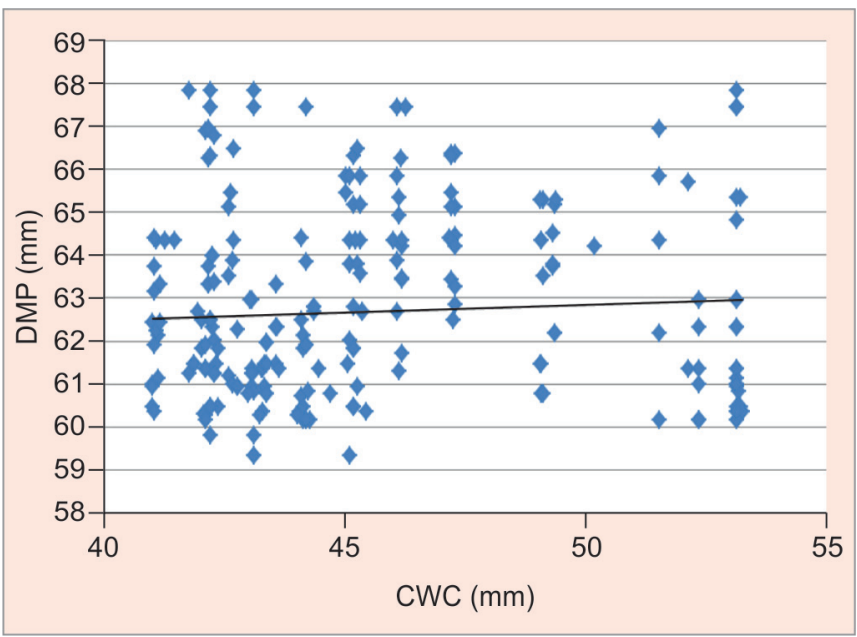

Graph 4: Correlation between CWC and DMP among males 


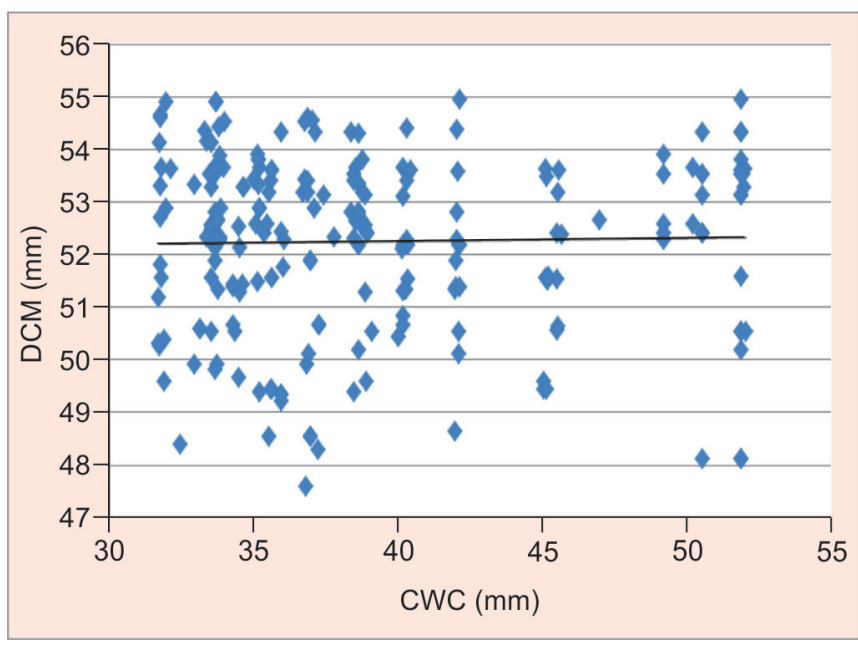

Graph 5: Correlation between CWC and DCM among males

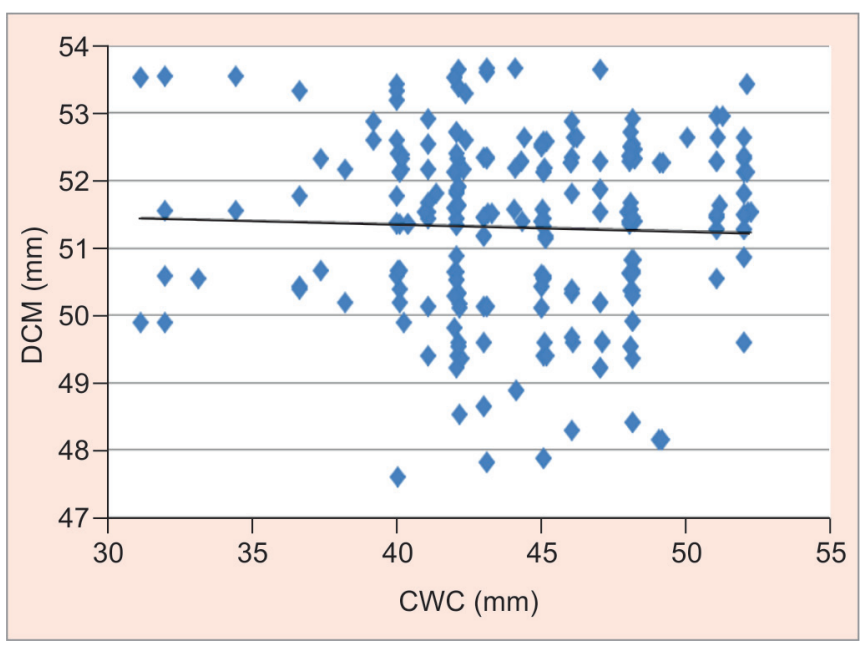

Graph 7: Correlation between CWC and DCM among females

\section{DISCUSSION}

Though a perfect smile is an important component of facial esthetics, it should be in proportion with the rest of the face. The relationship between various facial measurements and natural teeth could be used as a reliable guide

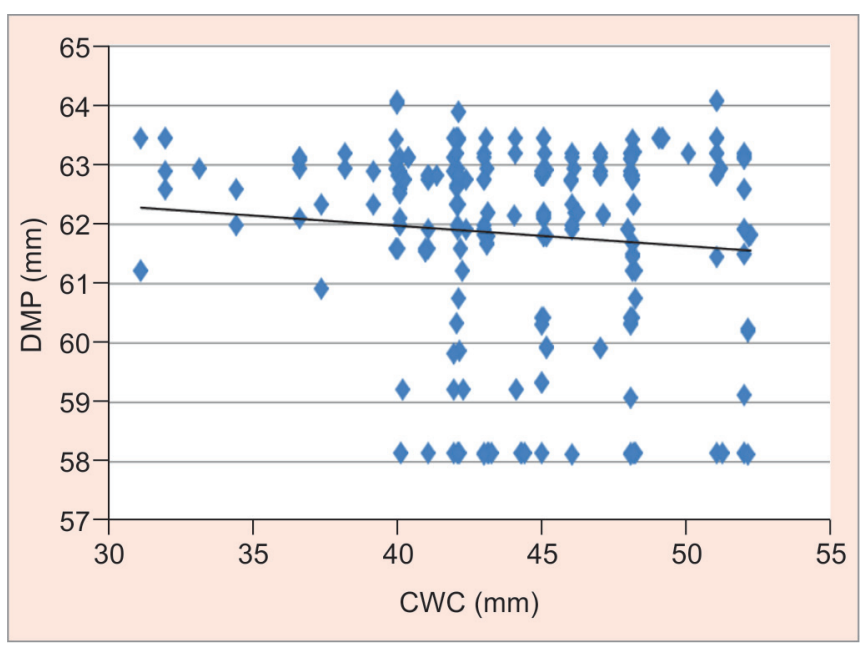

Graph 6: Correlation between CWC and DMP among females

to achieve an optimum esthetics. Gomes et $\mathrm{al}^{15}$ stated that the estimation of mesiodistal width of the maxillary frontal teeth is one of the most difficult aspects in complete denture therapy. Many studies have been performed to establish methods of estimating the combined mesiodistal width of upper anterior teeth to improve the complete denture esthetics. In previous studies, ${ }^{19,20}$ measurements were conducted on human extracted teeth. But, recent studies ${ }^{21-24}$ measured the clinical tooth dimensions using casts obtained from subjects or computer-based photographs or intraoral evaluations. While comparing these values, marked differences were noted between the actual and perceived dimensions of the anterior teeth. This difference was contributed by the curvature of the arch and angulations of the maxillary frontal teeth, in relation to the frontal plane of the subject's photograph. Hence, the intercanine width measurements were done on the stone cast with the caliper. India is a diverse country with various ethnic groups with each having different facial profiles. There is no dentofacial norm for use in prosthodontics that is representative of the Indian

Table 1: Descriptive statistics of the study subjects

\begin{tabular}{llll}
\hline Variables $(n=540)$ & Mean $\pm S D$ & Median $(I Q R)$ & Max-min \\
\hline Age (years) & $22.57 \pm 2.62$ & $23(4.00)$ & $30-19$ \\
Intercanine width (CCW) in mm & $45.04 \pm 4.21$ & $44.27(5.89)$ & $53.22-31.20$ \\
Interpupillary distance (DMP) in mm & $62.26 \pm 1.97$ & $62.32(2.00)$ & $67.80-58.12$ \\
Intercommissural distance (DCM) in mm & $51.79 \pm 1.56$ & $52.12(2.26)$ & $54.96-47.60$ \\
IPD/ICW & $1.39 \pm 0.14$ & $1.40(0.16)$ & $2.03-1.11$ \\
ICD/ICW & $1.16 \pm 0.12$ & $1.16(0.16)$ & $1.72-0.91$ \\
\hline
\end{tabular}

Table 2: Comparison of CWC, DMP, DCM, IPD/ICW and ICD/ICW ratio between males and females

\begin{tabular}{llllll}
\hline & $\begin{array}{l}C W C \\
(\text { mean } \pm S D)\end{array}$ & $\begin{array}{l}D M P \\
(\text { mean } \pm S D)\end{array}$ & $\begin{array}{l}\text { DCM } \\
(\text { mean } \pm S D)\end{array}$ & $\begin{array}{l}\text { DMP/CWC } \\
(\text { mean } \pm \text { SD })\end{array}$ & $\begin{array}{l}\text { DCM/CWC } \\
(\text { mean } \pm S D)\end{array}$ \\
\hline Male $(\mathrm{n}=277)$ & $45.59 \pm 3.83$ & $62.69 \pm 2.11$ & $52.25 \pm 1.63$ & $1.38 \pm 0.11$ & $1.15 \pm 0.10$ \\
Female $(\mathrm{n}=263)$ & $44.46 \pm 4.52$ & $61.82 \pm 1.70$ & $51.30 \pm 1.33$ & $1.41 \pm 0.16$ & $1.17 \pm 0.13$ \\
Mann-Whitney U-test & 312.5 & 325.0 & 221.0 & 360.0 & 361.5 \\
p-value & $0.004 \mathrm{~S}$ & $0.034 \mathrm{~S}$ & $0.0001 \mathrm{~S}$ & $0.852 \mathrm{NS}$ & $0.901 \mathrm{NS}$ \\
\hline
\end{tabular}

${ }^{*} \mathrm{NS}$ : Not significant; S: Significant 
Table 3: Spearman's correlation of CWC-DMP and CWC-DCM

\begin{tabular}{llllll}
\hline & \multicolumn{2}{c}{ CWC-DMP } & & \multicolumn{2}{c}{ CWC-DCM } \\
\cline { 2 - 3 } & Correlation coefficient $(r)$ & $p$-value & & Correlation coefficient $(r)$ & 0.471 NS \\
\hline Overall $(n=540)$ & 0.015 & $0.729 \mathrm{NS}$ & & 0.031 & 0.934 NS \\
Male $(\mathrm{n}=277)$ & 0.084 & $0.166 \mathrm{NS}$ & & -0.005 & 0.604 NS \\
Female $(\mathrm{n}=263)$ & -0.082 & $0.186 \mathrm{NS}$ & & -0.032 & \\
\hline
\end{tabular}

NS: Not significant

population. The present study aimed to determine if proportional relationship exists between the widths of the maxillary frontal teeth, the interpupillary distance, and the intercommissural width in central Indians. This study showed that males have a significantly higher mean value in all the parameters measured than the females. This finding is in agreement with other studies in which gender-based variations were observed for most racial groups. ${ }^{19,21,23}$ The reason may be due to the male physique dominance over the females irrespective of the age group. In this study, the mean intercommissural width was greater than the mean of the intercanine width measured. This finding was similar to the findings of Stephan, ${ }^{25}$ in which the DCM differed significantly from the CWC. It has been suggested that the distal surface of the natural upper canine can be considered to be located near the corner of the mouth, which further can be equated to the intercanine width. ${ }^{26}$ This guideline has been used in the selection of maxillary frontal teeth during bite registration in complete denture therapy. However, there are no such evidences to suggest the validity of this relationship. Several authors ${ }^{2-5}$ have made attempts to find a relationship between the maxillary frontal teeth and facial structures. The interpupillary distance has been suggested to relate the intercanine width and has been widely used for the selection of maxillary frontal teeth. Due to racial variations in facial proportions, a need exists to investigate the relationship between the intercanine width and the interpupillary distance for other racial groups.

The mean value of CWC ( $45.04 \mathrm{~mm})$ was found to be significantly high in male than female. This finding was almost similar to the findings of Al Wazzan ${ }^{12}(45.23 \mathrm{~mm})$. The value of the mean of the CWC, higher than the present study was reported in other studies. ${ }^{15,18}$ But in some studies, the values were found lower than the present study. ${ }^{5,27-29}$ The gender-based variations were also reported in the literature, ${ }^{5,12,18}$ as shown in the present study. But few studies have shown no gender based variations. ${ }^{15,27}$ The mean DMP of the subjects in the present investigation was $(62.26 \pm 1.97 \mathrm{~mm})$ for the total sample, which was similar to the findings of Latta et $\mathrm{al}^{4}(63.51 \mathrm{~mm})$ and Al-el-Sheikh et al ${ }^{18}(62.31 \pm 4.10)$. Cesario and Latta ${ }^{2}$ found a mean value of $59.16 \mathrm{~mm}$ in the subjects of United
States army, which was lower than the present study. Also, the higher mean values were reported. ${ }^{15}$ The variations in the mean values in the reported studies may be due to the ethnic and racial differences. In the present study, a sample of 540 subjects was investigated, which revealed an increased DMP values for male than female. These gender-based variations were also reported in some studies. ${ }^{15,18}$ The mean value of DCM in the present study was $51.79 \pm 1.56 \mathrm{~mm}$. Ibrahimagic et $\mathrm{al}^{30}$ found a mean value of $45.4 \mathrm{~mm}$ in their study, which was lower than the present investigation. Esan et al ${ }^{29}$ reported a mean value of $74.6 \pm 6.7 \mathrm{~mm}$ in Nigerian population, which was higher than the present study. Varjao and Nogueira ${ }^{16}$ studied intercommissural width in four racial groups and found to be $47.02 \mathrm{~mm}$ (White), $48.12 \mathrm{~mm}$ (Mulatto), $50.33 \mathrm{~mm}$ (Black), and $43.10 \mathrm{~mm}$ (Asian) respectively. These values were lower than the present study.

The correlation between the entire three variables studied were found to be weak. The correlation coefficient (R) between CWC and DMP for all subjects was 0.015; whereas for males and females, it was 0.084 and -0.082 respectively. Similarly, correlation coefficient (R) between CWC and DCM for all subjects was 0.031, whereas for males and females it was -0.005 and -0.032 respectively. The correlation of the studied variables in overall and in between the sexes was found to be not significant. Al-el-Sheikh and Al-Athel ${ }^{18}$ found a highly significant correlation $(r=0.3036)$ between CWC and DMP in Saudi population and when compared between the sexes, females showed significant correlation $(r=$ 0.2134 and $\mathrm{p}<0.001)$ than males. Esan et $\mathrm{al}^{29}$ reported a significant correlation $(r=0.24)$ between CWC and DCM in Nigerian population.

Although the correlation found in this investigation was weak, clinicians could use DMP and DCM to estimate the tentative position of the canine for fabrication of complete denture prosthesis for edentulous patients. Since the canine position is affected by many variables and so forth the CWC, it would be a mistake to claim that either facial landmark, i.e. DMP and DCM was proven superior by this investigational work. Adequate contouring the occlusion wax rim to achieve optimum lip support and occlusal vertical dimension and then marking the canine line must be considered as a tentative method. 
The final decision should be made while evaluating the appearance of each patient. Generally, facial appearance varies between different ethnic groups. Furthermore, it is not possible to confirm that each individual in this investigation was native Indian. People with Indian nationality may be of ethnic differences. Some may be a mixture of Hindu, Muslim, Sikh or Isai (Christian), which are predominant religious communities in India. Moreover, there might be other factors that influence the position of canine which were out of the scope of this investigation. Hence, facial landmarks cannot be too strongly emphasized when a clinician plans to deliver complete dentures with pleasing appearance. A combination of esthetics and phonetics outcome should be concerned while treating complete denture patients. The use of the papillary midpoints and the corners of the mouth for the selection of the artificial teeth width would lead, in general, to the selection of narrower teeth. The results suggest that the method is inaccurate for the studied population, rendering the worst esthetic result for the Indian group.

\section{CONCLUSION}

The study determined the mean measurements of some facial parameters among central Indians and showed no direct relationship between interpupillary distance, intercommissural width, and the combined mesiodistal width of maxillary frontal teeth. Therefore, interpupillary distance and intercommissural width should not be used in marking canine line during bite registration procedure. However, these facial measurements could be used to establish only tentative determination of the canine position for complete denture therapy. Esthetic and phonetic guidelines should be considered as adjutant parameters in verifying the combined width of upper frontal teeth. Within the limitations of this study, following conclusions can be drawn:

- Statistically significant difference between males and females exists for all the measured variables (DMP, DCM and CWC), i.e. males have bigger dimensions than females.

- The correlation coefficient between DMP-CWC and DCM-CWC was weak and not significant when measured for all subjects and for both the sexes.

- There was no significant difference between sexes for all the calculated ratios: DMP/CWC and DCM/CWC ( $p>0.05)$. However, the ratios 1.39 (DMP/CWC) and 1.16 (DCM/CWC) can be used as additional help for estimation of mesiodistal width of upper anterior teeth in the population studied.

\section{REFERENCES}

1. Scandrett FR, Kerber PE, Umrigar ZR. A clinical evaluation of techniques to determine the combined width of the maxillary anterior teeth and the maxillary central incisor. J Prosthet Dent 1982;48:15-22.

2. Cesario VA Jr, Latta GH Jr. Relationship between mesiodistal width of maxillary central incisor and interpupillary distance. J Prosthet Dent 1984;52:641-643.

3. Hoffman W Jr, Bomberg TJ, Hatch RA. Interalar width as a guide in denture tooth selection. J Prosthet Dent 1986;55: 219-221.

4. Latta GH Jr, Weaver JR, Conkin JE. The relationships between width of the mouth, interalar width, bizygomatic width and interpupillary distance in edentulous patients. J Prosthet Dent 1991;65:250-254.

5. Abdullah MA. Inner canthal distance and geometric progression as a predictor of maxillary central incisor width. J Prosthet Dent 2002;88:16-20.

6. Mavroskoufis F, Ritchie GM. Nasal width and incisive papilla as guides for the selection and arrangement of maxillary anterior teeth. J Prosthet Dent 1981;45:592-597.

7. Hickey JC, Zarb GA. Boucher's prosthodontic treatment for edentulous patient. 8th ed. St Louis: CV Mosby; 1980. p. 322-325.

8. Rahn AO, Heartwell CM Jr. Textbook of complete dentures. 5th ed. Philadelphia: Lea Febiger; 1993. p. 272.

9. Wehner PJ, Hickey JC, Boucher CO. Selection of artificial teeth. J Prosthet Dent 1967;18:222-232.

10. Basker RM, Davenport JC. Prosthetic treatment of the edentulous patient. Oxford: Blackwell Munksgaard, Blackwell Publishing Company, 2002. p. 172-202.

11. Smith BJ. The value of the nose width as an esthetic guide in prosthodontics. J Prosthet Dent 1991;65:250-254.

12. Al Wazzan KA. The relationship between intercanthal dimension and the widths of maxillary anterior teeth. J Prosthet Dent 2001;86:608-612.

13. Lucas WP, Pryor HB. Range and standard deviations of certain physical measurements in healthy children. J Pediatr 1935;6:533-545.

14. Bindra B, Basker RM, Besford JN. A study of the use of photographs for denture tooth selection. Int J Prosthodont 2001;14:173-177.

15. Gomes VL, Goncalves LC, Parado CJD, Junior IL, et al. Correlation between facial measurements and the mesiodistal width of the maxillary anterior teeth. J Esthet Restor Dent 2006;18:196-205.

16. Varjão FM, Nogueira SS. Intercommissural width in 4 racial groups as a guide for the selection of maxillary anterior teeth in complete dentures. Int J Prosthodont 2005;18:513-515.

17. Hasanreisoglu U, Berksun S, Aras K, Arslan I. An analysis of maxillary anterior teeth: facial and dental proportions. J Prosthet Dent 2005;94:530-538.

18. Al-el-Sheikh HM, Al-Athel MS. The relationship of interalar width, interpupillary width and maxillary anterior teeth width in Saudi population. Odontostomatol Trop 1998;21: 7-10.

19. Gillen RJ, Schwartz RS, Hilton TJ, Evans DB. An analysis of selected normative tooth proportions. Int J Prosthodont 1994; 7:410-417.

20. Ash MM. Wheeler's atlas of tooth form. 5th ed. Philadelphia; Saunders; 1984. p. 24-25. 
21. Sterret JD, Oliver T, Robinson F, Fortson W, Knaak B, Russel CM. Width/length ratios of normal clinical crowns of maxillary anterior dentition in man. J Clin Periodontol 1999; 26:153-157.

22. Magne P, Belser U. Bonded porcelain restorations in anterior dentition: a biometric approach. Chicago: Quintessence; 2002. p. 64-70.

23. Owens EG, Goodacre JC, Loh PL, Hanke G, Okamura M, Jo k, et al. A multicenter interracial study of facial appearance. Part 2: a comparison of intraoral parameters. Int J Prosthodont 2002;15:283-288.

24. Iscan MY, Kedici PS. Sexual variation in buccolingual dimensions in Turkish dentition. Forensic Sci Int 2003;137:160-164.

25. Stephan CN. Facial approximation: An evaluation of mouthwidth determination. Am J Phys Anthropol 2003;121:48-57.
26. George AZ, Charles LB, Judson CH, Gunnar EC. Boucher's Prosthodontic treatment for edentulous patients. 10th ed. The CV Mosby Company. p. 333.

27. Abdullah AM, Stipho HD, Tolic YF, et al. The significance of inner canthal distance in prosthodontics. SDJ 1997;9: 36-39.

28. Shillinburg HT, Kaplan MJ, Grace CS. Tooth dimensions: a comprehensive study. J South Calif Dent Asso; 1972; p. 40-83.

29. Esan TA, Oziegbe OE, Onapokya HO. Facial approximation: evaluation of dental and facial proportions with height. African Health Sciences 2012;12(1):63-68.

30. Ibrahimagic L, Celebic A, Jerolimov, et al. Correlation between the size of maxillary frontal teeth, the width between Alae Nasi and the width between corners of the lips. Acta Stomat Croat 2001;35:175-179. 